\title{
Cartilage Framework Fixation with 2-Octyl Cyanoacrylate in a Prelaminated Radial Forearm Free Flap Total Auricular Reconstruction
}

\author{
Cara Reitz ${ }^{1}$, Chris England ${ }^{2}$, Owen N. Johnson III ${ }^{3,4}$ \\ 1. Surgery, William Beaumont Army Medical Center, El Paso, USA 2. Otolaryngology, Proliance Surgeons, Mount \\ Vernon, USA 3. Surgery, Uniformed Services University of the Health Sciences, F. Edward Hébert School of Medicine, \\ Bethesda, USA 4. Surgery, Texas Tech University Health Sciences Center El Paso, Paul L. Foster School of Medicine, El \\ Paso, USA
}

Corresponding author: Owen N. Johnson III, owenjohnson3@hotmail.com

\begin{abstract}
Autologous total auricular reconstruction requires an intricately sculpted, curved, and stacked cartilaginous framework implanted under healthy vascularized tissue. The ideal fixation technique would be readily available, easy to deploy, and free of complications. Commonly used sutures can fracture fragile pieces, inadequately maintain shape, or migrate. Steel wire can erode through soft tissues, extrude, fracture, or become infected. We successfully used 2-octyl cyanoacrylate alone to fixate an autologous costal cartilage framework designed for a total auricular reconstruction in an adult trauma patient. We had no sutures or wires in the final construct. The key aspects of our technique included the following: use of small aliquots, application only at cartilage-to-cartilage interfaces, use of temporary shaping (needles and lasso sutures), and avoidance of excess spillage of adhesive on any portion that would directly contact soft tissue. The framework was implanted into a prelaminated radial forearm free flap, which was then transferred to the head and neck region at a second stage. At two-year follow-up, the framework held satisfactory shape without any complications such as resorption, exposure, or infection.
\end{abstract}

Received 11/25/2019

Review began $11 / 26 / 2019$ Review ended 12/10/2019 Published 12/15/2019

() Copyright 2019 Reitz et al. This is an open access article distributed under the terms of the Creative Commons Attribution License CC-BY 3.0., which permits unrestricted use, distribution, and reproduction in any medium, provided the original author and source are credited.
Categories: Otolaryngology, Plastic Surgery, Miscellaneous

Keywords: ear reconstruction, cartilage framework, prelaminated, microsurgery, head and neck, reconstruction, adhesives, dermabond, cyanoacrylate, fixation

\section{Introduction}

A detailed cartilaginous framework must be intricately sculpted, curved, stacked, and then fixated in autologous total auricular reconstruction. Sutures can fracture fragile pieces of cartilage, leading to ingrowth and resorption. Steel wire can extrude. Rhinoplasty surgeons have cautioned against using bioadhesives to stabilize cartilage grafts due to prolonged inflammation and infection, although data have actually been mixed or confounded by other variables [1]. We report successfully employing 2-octyl cyanoacrylate (Dermabond, Ethicon, Somerville, NJ) as the sole fixation method of a costal cartilage auricular framework in a prelaminated radial forearm free flap (RFFF) without complication.

\section{Case Presentation}

A 20-year-old female suffered traumatic avulsion of the left auricle with diffuse hypertrophic scarring of the surrounding soft tissue areas. External auditory canal cicatricial stenosis was associated with subjective early hearing loss. Treatment of the stenosis was indicated. The patient considered prosthetics, but free tissue transfer was deemed the best option. Local soft tissues were inadequate as reliable flap donors or for stable coverage of osseointegrated hardware.

We discussed a multistage total reconstruction using an autologous costal cartilaginous framework prelaminated into a right RFFF. This multimodality plan also included targeted triamcinolone acetonide injections and meatoplasty.

Cartilage was harvested from the right synchondrosis. The framework design was based on the unaffected contralateral ear (Figure 1). 


\section{Cureus}
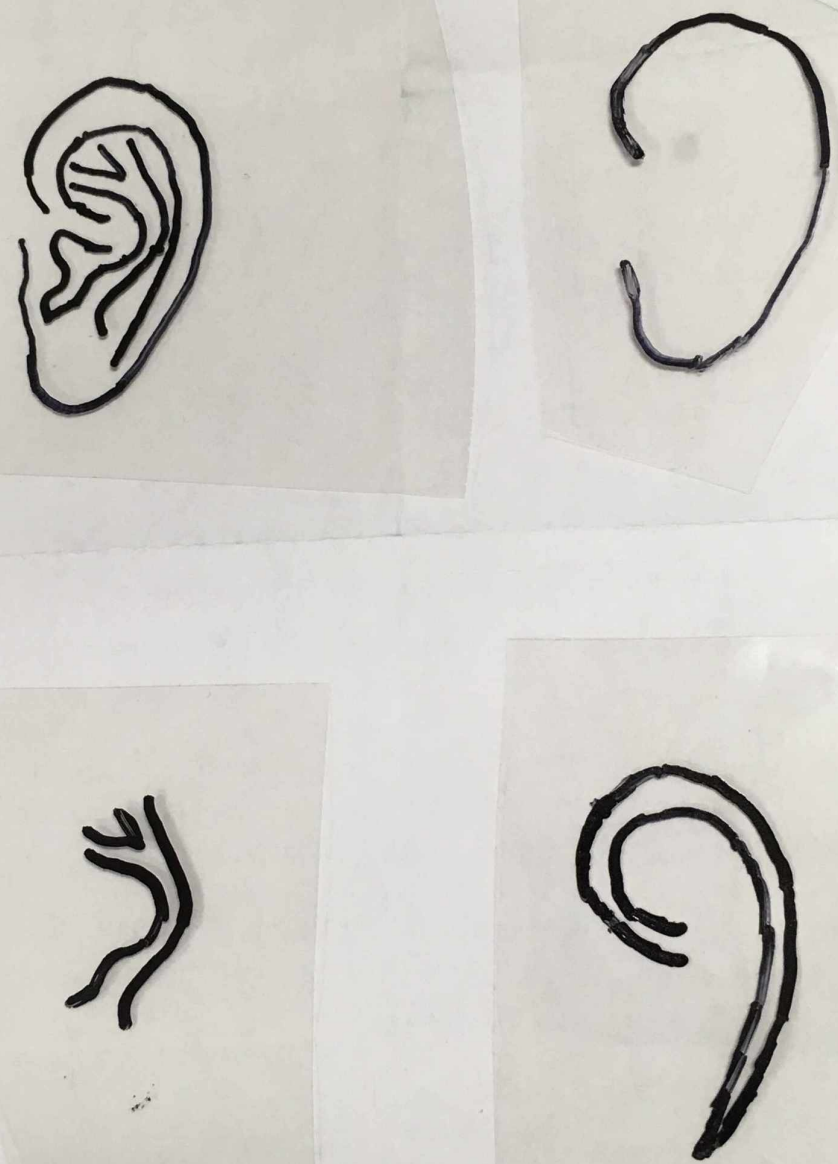

FIGURE 1: Mirrored templates based on the unaffected ear used in framework design.

The framework was constructed using a modified Nagata technique. To ensure adequate projection, multiple pieces were stacked. Driving needles and sutures into the fragile pieces would have risked fracture of the precious cartilage.

We decided to use fine syringe needles for initial shaping along the perimeter of the framework, similar to concrete stakes. 5-0 monofilament polypropylene sutures were used for lasso pieces as needed. We applied small aliquots of Dermabond to cartilage-to-cartilage interfaces. We took care to avoid spilling excess material onto parts of the framework that would contact soft tissue (Figure 2). 


\section{Cureus}

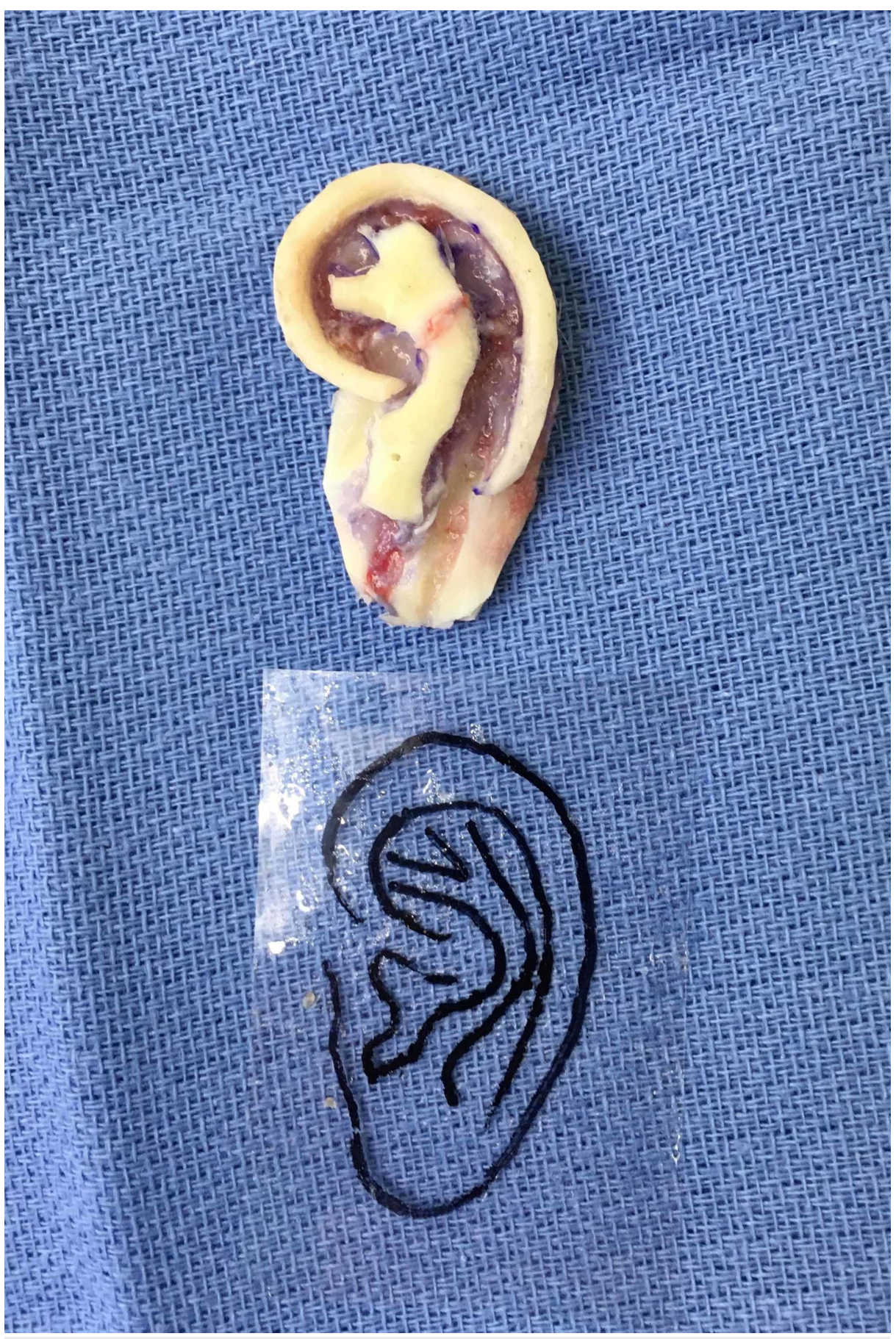

FIGURE 2: Intraoperative image of autologous costal cartilage framework prior to further carving and refinement ahead of implantation into right forearm. No sutures or wires were used for fixation.

Once completed, the framework was intact and solid, holding good shape without the need for any sutures or wires. This was implanted into the suprafascial plane of a planned RFFF, ulnar to the flexor carpi radialis tendon, through an ulnar skin incision. Sensory nerves were preserved (Figure 3). 


\section{Cureus}

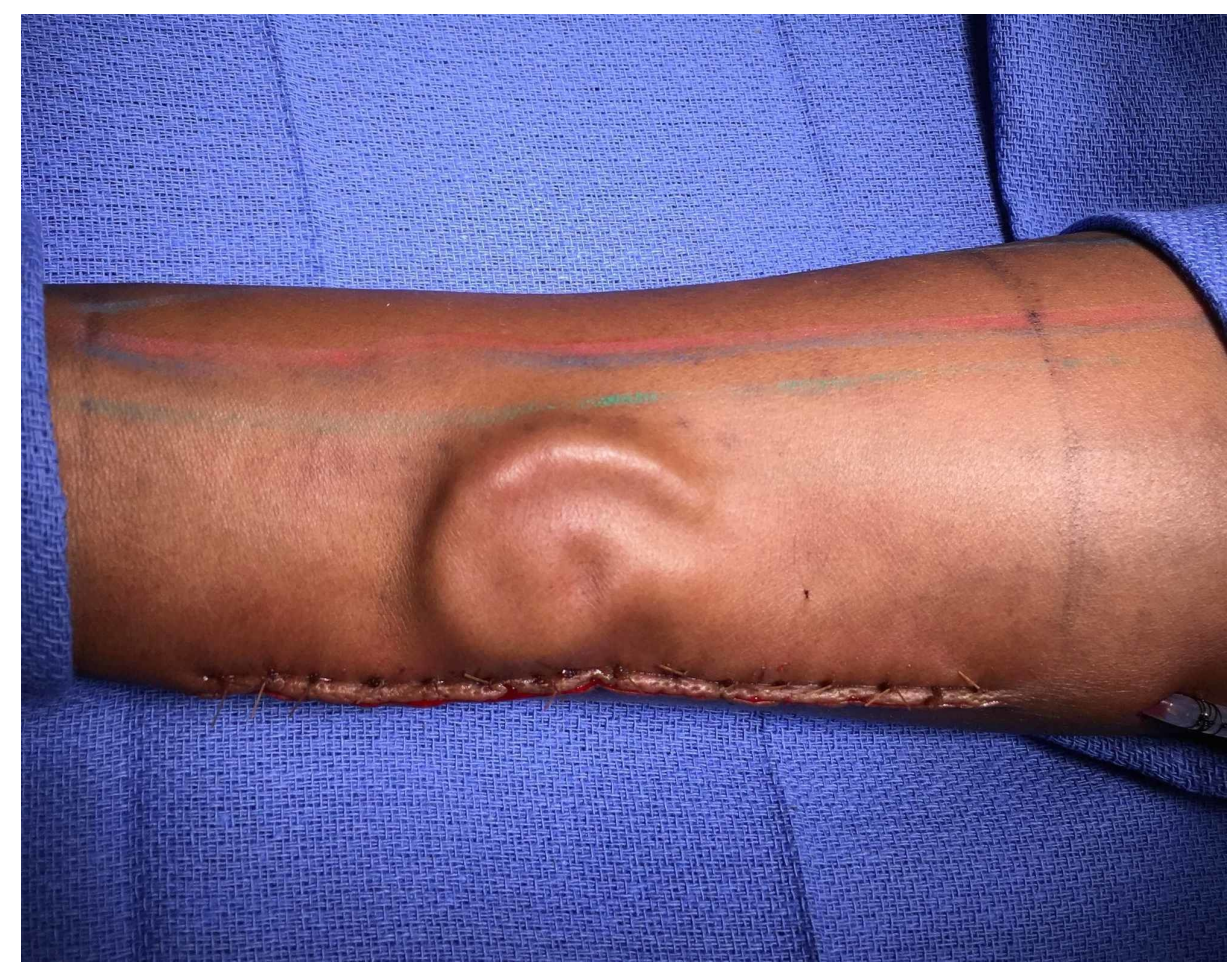

FIGURE 3: The framework was implanted into the suprafascial plane of a right radial forearm free flap and allowed to mature for one year.

There were no complications, and the framework matured in the forearm for one year. It maintained its shape with no resorption. There was normal edema and inflammation, but over time the soft tissue contracted over the framework and definition improved. The patient had no seroma, hematoma, tissue breakdown, infection, or foreign body reaction.

At the second stage, the right RFFF was transferred to the left facial vessels. Redundant skin and fascia were used at inset to elevate the construct from the mastoid. The reconstructed ear's height, lateral projection, and other measurements such as neo-helix-mastoid angle, neocephaloauricular and neo-scaphaconchal angles were carefully matched to the uninjured side (Figure 4). At two-year follow-up, the flap, with its intact framework, was healthy and ready for additional debulking and refinement. 


\section{Cureus}

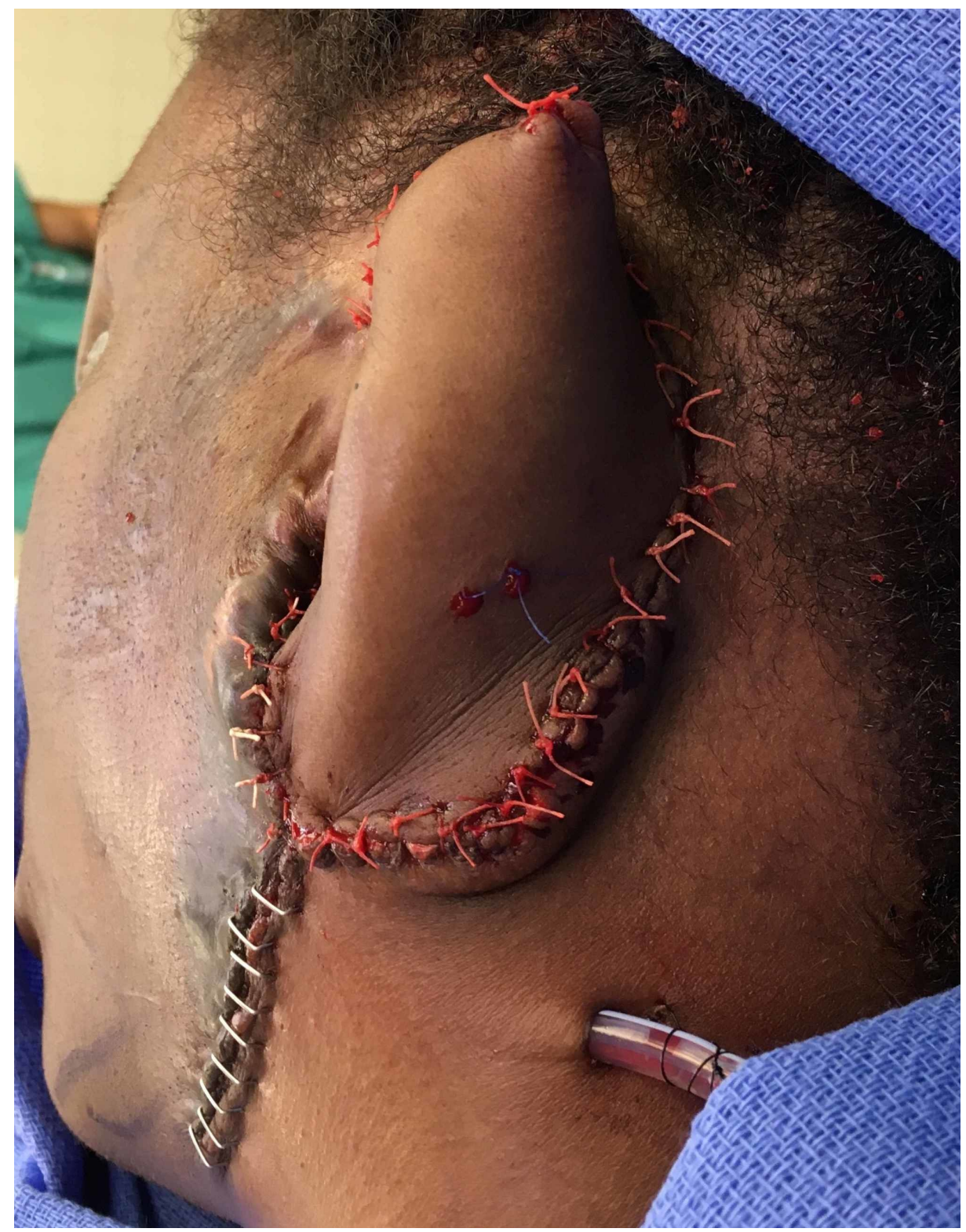

\section{FIGURE 4: On-table appearance of the prelaminated flap upon transfer}

to the head and neck region.

\section{Discussion}

Total ear reconstruction is considered for traumatic avulsion, burns, microtia, or following tumor extirpation [2-5]. Planning must consider framework, soft tissue coverage, and patient characteristics and goals.

Prosthetics that rely on osseointegrated hardware require healthy bone and stable soft tissue coverage. Porous polyethylene is available as a synthetic framework, but complications include failed osseointegration, delayed healing, dehiscence, device fracture, infection, and need for repeat operations $[6,7]$.

Long et al. reviewed complications after autologous cartilage auricular reconstruction [8]. These included unsatisfactory results, wire or suture extrusion, and cartilage resorption as well as infection, hematoma, skin necrosis, framework exposure, framework fracture, and facial nerve injury. Their review noted that wire fixation was correlated with higher rates of extrusion, especially at longer follow-up intervals.

Extrusion and infection are also possible with suture techniques, especially when permanent sutures are used. Sakamoto compared different fixation materials and found the lowest complication rate to be with absorbable sutures [9]. 
Ma et al. described using 5-0 steel wires to suture and splice their sculptured frameworks for microtia reconstruction [4]. They noted the need for caution to avoid fracturing the cartilage, which can occur when passing suture or wire, and often is worse when passing through multiple layers. When fractured, connective tissue is allowed to infiltrate the cartilage and can ultimately lead to resorption, affecting functional and aesthetic outcomes $[4,10]$. The Nagata method utilizes approximately 80 pieces of 38-gauge stainless steel wire [11].

We were interested in alternative fixation methods that could avoid the need for sutures or wires. Dermabond has been used in skin closures, ossicular reconstruction, laryngeal repairs, reconstructive rhinoplasty, dental reconstruction, radiologic embolization, dural repairs, endoscopic treatment of enterocutaneous fistulas, management of pulmonary air leaks, and corneal perforation repairs $[10,12,13]$. It is a long-chain adhesive that exhibits less tissue toxicity, confers more microbial resistance, and contains additional stabilizers for improved tensile strength compared to earlier-generation versions $[13,14]$.

Gall et al. reported postoperative septal abscess following use of Dermabond in septorhinoplasty [1]. They, however, used a polydioxanone plate secured with both Dermabond and suture in their repair, which may confound any attribution of infection to the use of adhesive alone. Min and Jang also found a higher complication rate when using adhesives for tip grafting in rhinoplasty [15]. Open rhinoplasty is known to be associated with significant swelling, especially when foreign materials are used under a thin skin and soft tissue envelope. The authors commented that their complications were often observed when multiple layers of cartilage were required, larger amounts of adhesive were used, and high amounts were spilled into surrounding tissues.

Early animal studies showed N-octyl cyanoacrylate elicited similar inflammatory responses and had similar migration propensity as sutures [10,12]. Its advantages include ease of application, decreased damage to cartilage, and removal of needles from the operative field. In areas where suturing is not accessible such as in posterior cricoid fractures, Dermabond fixation of cartilage shows a definite advantage [16]. Seo et al. had favorable results with no significant protrusions, dislocations, or unusual inflammation after rhinoplasty in Asian patients [14]. Dabb et al. also reported good outcomes with no complications in a cohort of nine patients [13].

\section{Conclusions}

The use of 2-octyl cyanoacrylate was successfully used in the construction of our auricular framework for prelaminated free flap total ear reconstruction, chosen for its ease of application, microbial resistance, and tensile strength. We avoided using any sutures or wire, and did not fracture any cartilage pieces. Postoperative healing was not negatively impacted compared to standard fixation, and the patient experienced no infectious or excessive inflammatory complications. The cornerstones of our technique included the following: use of small aliquots, application only at cartilage-to-cartilage interfaces, use of temporary shaping (needles and lasso sutures), and avoidance of excess spillage of adhesive on any portion that would directly contact soft tissue.

\section{Additional Information \\ Disclosures}

Human subjects: Consent was obtained by all participants in this study. Conflicts of interest: In compliance with the ICMJE uniform disclosure form, all authors declare the following: Payment/services info: All authors have declared that no financial support was received from any organization for the submitted work. Financial relationships: All authors have declared that they have no financial relationships at present or within the previous three years with any organizations that might have an interest in the submitted work. Other relationships: All authors have declared that there are no other relationships or activities that could appear to have influenced the submitted work.

\section{References}

1. Gall R, Bevans S, Robitschek J: Postoperative nasal septal abscess following use of 2-octylcyanoacrylate and polydioxanone plate in open septorhinoplasty: a case series. Ann Otol Rhinol Laryngol. 2017, 126:688-692. 10.1177/0003489417727013

2. Schiavon M, Cagnoni G: Salvage of an amputated ear temporarily lodged in a forearm . Plast Reconstr Surg. 1995, 96:1698-1701. 10.1097/00006534-199512000-00027

3. Bhandari PS: Total ear reconstruction in post burn deformity. Burns. 1998, 24:661-70. 10.1016/s03054179(98)00093-X

4. Ma T, Xie F, Zhang Z: Modified 2-stage method for auricular reconstruction . Ann Plast Surg. 2018, 80:628633. 10.1097/SAP.0000000000001413

5. Finical SJ, Johnson CH: Reconstruction after extirpation of the auricle. J Reconstr Microsurg. 2001, 17:325329. 10.1055/s-2001-16023

6. Romo T 3rd, Morris LG, Reitzen SD, Ghossaini SN, Wazen JJ, Kohan D: Reconstruction of congenital microtia-atresia: outcomes with the Medpor/bone-anchored hearing aid approach. Ann Plast Surg. 2009, 62:384-389. 10.1097/SAP.0b013e31819fae51

7. Agarwal CA, Johns D, Tanner PB, Andtbacka RHI: Osseointegrated prosthetic ear reconstruction in cases of 


\section{Cureus}

skin malignancy: technique, outcomes, and patient satisfaction. Ann Plast Surg. 2018, 80:32-39. 10.1097/SAP.0000000000001223

8. Long X, Yu N, Huang J, Wang X: Complication rate of autologous cartilage microtia reconstruction: a systematic review. Plast Reconstr Surg Glob Open. 2013, 7:57. 10.1097/GOX.0b013e3182aa8784

9. Sakamoto A, Kiyokawa K, Rikimaru H, Watanabe K, Nishi Y: An investigation of the fixation materials for cartilage frames in microtia. J Plast Reconstr Aesthet Surg. 2012, 65:584-589. 10.1016/j.bjps.2011.10.018

10. Fung RQ, Ronis ML, Mohr RM: Use of butyl-2-cyanoacrylate in rabbit auricular cartilage . Arch Otolaryngol. 1985, 111:459-464. 10.1001/archotol.1985.00800090073012

11. Olshinka A, Louis M, Truong TA: Autologous ear reconstruction. Semin Plast Surg. 2017, 31:146-151. 10.1055/s-0037-1603959

12. Brown PN, McGuff HS, Noorily AD: Comparison of N-octyl-cyanoacrylate vs suture in the stabilization of cartilage grafts. Arch Otolaryngol Head Neck Surg. 1996, 122:873-877.

10.1001/archotol.1996.01890200063014

13. Dabb RW, Gaffield JW, Camp LA: Use of cyanoacrylate (super glue) for the fixation and prefabrication of nasal cartilage grafts. Aesthet Surg J. 2001, 21:328-333. 10.1067/maj.2001.117709

14. Seo JO, Kwon JW, Kim SK, Lim JS, Park DJ: A new nose tip-defining technique for Asians using autologous cartilage prefabricated with octyl-2-cyanoacrylate adhesive. Arch Facial Plastic Surg. 2010, 12:252-256. 10.1001/archfacial.2010.53

15. Min JY, Jang YJ: Use of 2-octylcyanoacrylate (Dermabond) tissue adhesive for tip graft fixation in open rhinoplasty. Otolaryngol Head Neck Surg. 2011, 145:737-741. 10.1177/0194599811419094

16. Standlee AG, Rogers DJ: Novel management of an isolated comminuted cricoid cartilage fracture . Ear Nose Throat J. 2016, 95:452-453. 